\title{
Upacara Tantulak Ambun Rutas Matei Pada Masyarakat Hindu Kaharingan (Persfektif Hukum Hindu)
}

\author{
Mariatie.S.Ag.,M.Si \\ IAHN Tampung Penyang Palangka Raya \\ m mariatie@yahoo.com
}

\begin{abstract}
Abstrak
Upacara kematian di kalangan umat Hindu Kaharingan yang disebut dimulai dengan proses perawatan jenazah, penguburan secara ritual dan proses tantulak Ambun Rutas Matei. Upacara tantulak Ambun Rutas Matei dilakukan tiga hari setelah upacara penguburan dengan tujuan untuk mengantarkan arwah Liau Haring Kaharingan dari lewu pasahan raung menuju Bukit Nalian Lanting tempat penantian bersama Nyai Bulu Indu Rangkang untuk sementara ditiwahkan dan sekaligus membersihkan keluarga duka dari sial atau rutas kapali belum artinya dari segala pantangan hidup yang mengakibatkan kematian, hidup sial, segala macam penyakit yang menimpa keluarga. Selain itu, upacara tantulak juga bertujuan untuk memulihkan keseimbangan magis, menjauhkan segala macam marabahaya dan menghilangkan segala kemalangan atau kesialan dan hal-hal yang tidak baik yang dapat timbul pada keluarga Tarantang Nule (keluarga duka) maupun pada seluruh warga di kampung.

Adanya upacara Tantulak Ambun Rutas Matei ini berawal dari proses Kematian manusia dimuka bumi ini (Lewu Injam Tingang Rundung Nasih Napui Burung) sebagai tempat sementara untuk kehidupan keturunan Raja Bunu.

Kata Kunci : Upacara, Tantulak Ambun Rutas Matei, Masyarakat. Perspektif, Hukum Hindu.
\end{abstract}

\section{Pendahuluan}

Setiap warga negara dijamin kebebasannya memeluk dan menjalankan ajaran agamanya seperti yang tercantum pada Pasal 29 UUD 1945. Seluruh rakyat Indonesia yakin dan percaya bahwa Tuhan itu Esa (tunggal) dan 
Maha Kuasa. Dengan adanya keyakinan dan kepercayaan itu, maka masyarakat bangsa Indonesia memberikan kebebasan yang sangat mutlak dan paling azasi untuk memilih dan melaksanakan ajaran agama sesuai dengan kepercayaannya.

Begitu pula halnya dengan umat Hindu yang merupakan bagian dari masyarakat bangsa Indonesia ini, tentunya mempunyai hak dan kewajiban yang sama dan setara dengan penganut agama lainnya, baik hak dan kewajiban dalam menjalankan peribadatan dan persembahan maupun dalam pelaksanaan upacara-upacara ritual keagamaan lainnya yang didasari dengan keyakinan dan kepercayaannya. Tuhan menurunkan ajarannya penuh dengan yajna karena Yajna adalah merupakan suatu kemuliaan, kemakmuran dan kesejahteraan yang abadi, karena yajna merupakan ajaranajaran kesucian dan sangat mulia dihayati serta diamalkan dalam kehidupan sehari-hari. Setiap agama telah mengajarkan tentang kebajikan, supaya manusia itu berahlak, berbudi pekerti yang luhur dan memiliki Tata Karama yang baik. maka hendaknya Umat Hindu Kaharingan di Kalimantan Tengah benar-benar dapat menghayati dan mendalami ajaran agama terutama tentang tata cara upacara ritual keagamaan. Didalam ajaran agama Hindu dilakukan sesuai dengan Tempat, Waktu, Keadaan daerah setempat yang 
dikenal dengan istilah " Desa, Kala, Patra "yang merupakan doktrin yang luhur dan strategis bagi Umat Hindu/ Hindu Kaharingan.

Menurut Nyoman S. Pendit dalam bukunya Aspek-aspek Agama Hindu menyatakan bahwa " Desa artinya tempat kita berada, Kala artinya waktu saat kita berada, Kala Patra artinya keadaan atau situasi, kondisi dimana kita berada." (Nyoman S. Pendit . 1993 : 108).

Dengan adanya penyatuan terhadap doktrin tersebut, maka ajaran agama Hindu itu pun juga harus sesuai dengan tempat waktu dan keadaan (situasi) dimana umat Hindu berada. Bagi intern umat Hindu perbedaanperbedaan itu tidak perlu dipermasalahkan bahkan merupakan kebanggaan dan sumber kekayaan budaya Hindu yang menarik dan unik untuk dipelihara dan dilestarikan. Perbedaan itu baik menyangkut nama, istilah, tata cara upacara (upakara), maupun bahasa dan susunan suatu upacara ritualnya, dapat dilihat di Pulau Kalimantan itu mempunyai ciri khas tersendiri sesuai dengan Daerah Aliran Sungai ( DAS ) masing-masing.

Kalimantan Tengah adalah sebuah provinsi yang ada di Indonesia. Di sana ada beberapa masyarakat yang diupayakan untuk berkembang sesuai budaya dan tradisi setempat salah satu diantaranya adalah budaya Dayak Ngaju khususnya penganut agama Hindu Kaharingan yang selalu meyakini adat tradisi kematian bernuansa ritual yang selalu dilakukan oleh nenek 
moyang pada jaman dulu. Masyarakat di Indonesia pada umumnya, mereka juga mempercayai bahwa kehidupan manusia selalu diiringi dengan masamasa kritis, yaitu suatu masa yang penuh dengan ancaman dan bahaya (Koentjaraningrat, 1985; 67).

Masa peralihan dari tingkat kehidupan yang satu ke tingkat kehidupan lainnya dari manusia masih berupa janin sampai meninggal dunia. Oleh karena masa-masa tersebut dianggap sebagai masa yang penuh dengan ancaman dan bahaya, maka diperlukan adanya suatu usaha untuk menetralkannya, sehingga dapat dilalui dengan selamat. Usaha tersebut diwujudkan dalam bentuk upacara ritual yang kemudian dikenal sebagai daur hidup (upacara lingkaran hidup individu) yang meliputi: kelahiran, kelahiran dan kematian.

Kematian atau seseorang meninggal, berarti hubungan dengan dunia nyatanya telah putus dan ia dikatakan kembali ke alam baka. Kematian dinyatakan sebagai sebuah proses kembalinya setiap mahluk hidup termasuk didalamnya adalah manusia, yang sudah ditakdirkan oleh Ranying Hatalla Langit/Tuhan Yang Maha Esa dengan dibatasi oleh-Nya dalam hal umur.

Ranying Hatalla Langit/Tuhan Yang Maha Esa, sang pencipta kelahiran dan kematian yang mempunyai kekuasaan didalam menentukan status 
batas usia, yang tidak dapat diramal oleh manusia biasa, kapan waktunya yang tepat seseorang berpulang kedunia akhirat. Didalam perjalanan kematian tersebut tidak ada ketentuan yang pasti terhadap seseorang tidak ada pilih kasih, tidak ada perbedaaan kaya atau miskin semuanya kelak menuju kearah kematian sesuai dengan kehendak takdir.

Setiap sesuatu yang dilahirkan tentunya sudah mempunyai takdir untuk mati. Pada prinsipnya bahwa bagi seseorang yang memiliki tubuh/jasmani maka ia akan dikatakan mati (meninggal) apabila ia sudah tidak bernyawa lagi yang disebut menurut Hindu Kaharingan yaitu Manalian Lanting Lewu Ijam Tingang Rundung Nasih Napui Burung. Sedangkan menurut pandangan Preusz tentang ritus kematian bahwa arti ritus dan upacara dengan anggapan bahwa rangkaian ritus kematian menguraikan bahwa konsep manusia mengenai hidup dan maut sebenarnya diciptakan dan dikembangkan sendiri oleh manusia dengan ritus kematian sebagai sumbernya, sedangkan menurut Van Genep menguraikan bahwa ritus dan upacara religi secara universal pada azasnya berfungsi sebagai aktifitas untuk menimbulkan kembali semangat kehidupan sosial antara warga masyarakat (Koentjaraningrat, 1987 :64-74).

Setiap sesuatu yang dilahirkan tentunya sudah mempunyai takdir untuk mati, tidak ada yang kekal didunia ini. Pada prinsipnya bahwa bagi 
seseorang yang memiliki tubuh/jasmani maka ia akan dikatakan mati (meninggal) apabila ia sudah tidak bernyawa lagi. Sebagaimana proses kematian dalam sudut pandang hukum Hindu yang tertulis dalam Kitab suci Panaturan pasal 56 yang berbunyi : Bawi Ayah Nantu Ajar Auh Talatah Tantulak Ambun Rutas Matei Ayat 2 dan 3 berbunyi :

(2) Ranying Hatalla ma-nyahuan Bawi Ayah nantuajar palus malalus gawi marasih nantulak rutas kapali belum intu pampatei, palus kea hagahan Liau Haring Kaharingan lumpat Lewu Bukin Nalian Lanting mentai katika tinai hagagahan ie lumpat Lawang Lewu Tatau.

Artinya :

Ranying Hatalla Langit memerintah Bawi Ayah mangajar langsung melakukan upacara penyucian terhadap sial pantangan akibat kematian sekaligus tentang tatacara mengantar Liau Haring Kaharingan (Almarhum) ke Lewu Bukit Nalian Lanting dan di sana Ia menunggu saatnya di antar lagi menuju Lewu Tatau (alam keabadian, Kesempurnaan dan kebebasan).

(3) Huang katika Bawi Ayah natuajar, ulun kalunen hete ewen mampingat panakan utus Raja Bunu te ije belum huang Pantai Danum Kalunen, uka ewen mingat tutu-tutu auh peteh Ranyisng Hatalla Langit tahiu ampin panjulanan ewen buli haluli manalih Ranying Hatalla Langit, iete manumun ampi ewen tesek dumah bara IE, kalute kea ampin panjulanan ije ihuru awi ewen buli IE.

Artinya :

Pada waktu Bawi Ayah mengajarkan, disitu mereka mengingatkan kepada seluruh keturunan Raja Bunu yang hidup di Pantai Danum Kalunen, agar mereka sungguh-sungguh ingat pada semua firman dan petunjuk Ranying Hatalla Langit tentang tatacara mereka datang dari DIA, demikian pula Jalan yang dilalui oleh mereka kembaliNYA.

Berdasarkan pasal 56 ayat 2 dan 3 ini menyatakan bahwa kematian merupakan takdir yang sudah ditentukan oleh Ranying Hatalla Langit yang merupakan jalan untuk kembali kepadaNYA pada saat waktu yang telah 
ditentukan oleh Ranying Hatalla Langit. Kematian atau seseorang meninggal, berarti hubungan dengan dunia nyatanya telah putus dan ia dikatakan kembali ke alam Tuhan. Kematian dinyatakan sebagai sebuah proses kembalinya setiap mahluk hidup termasuk didalamnya adalah manusia, yang sudah ditakdirkan oleh Ranying Hatalla Langit/Tuhan Yang Maha Esa dengan dibatasi oleh-Nya dalam hal umur. Pada saat kembali roh liau haring Kaharingan kepada kemahakuasaan Ranying Hatalla/Tuhan Yang Maha Esa melalui proses sebagaimana yang diajarkan melalui Bawi Ayah yang tertulis dalam Kitab Suci Panaturan sebagai sumber Hukum Hindu.

\section{PEMBAHASAN}

\section{A. Proses Upacara Tantulak Ambun Rutas Matei}

\section{Persiapan Peralatan Upacara Tantulak Ambun Rutas Matei}

Didalam pelaksanaan upacara Tantulak Ambun Rutas Matei ini maka sebelum upacara dilaksanakan yaitu sesudah tiga hari setelah upacara Penguburan Arwah Liau Haring Kaharingan. Maka perlu dipersiapan berbagai sarana dan prasarana untuk pelaksanaan upacara Tantulak Ambun Rutas Matei tersebut. Biasanya untuk sarana dan prasarana ini terlebih dahulu keluarga duka akan berkonsultasi dengan Basir Upu yang akan memimpin upacara Tantulak Ambun 
Rutas Matei mengenai apa-apa saja yang harus dipersiapkan oleh pihak keluarga duka.

Sarana dan prasarana yang harus dipersiapkan didalam pelaksanaan upacara Tantulak Ambun Rutas Matei yaitu :

a. Menentukan Basir yang akan memimpin upacara Balian Tantulak Ambun Rutas Matei tersebut yang biasanya dilaksanakan minimal oleh 3 Orang Basir, yang meliputi 1 (satu) Orang Basir Upu, dan 2 (dua) Orang Basir Pengapit.

b. Katil (tempat duduk bagi para basir) yang telah dihias sedemikian rupa dengan berbagai macam kain berwarna warni.

c. Memasang Kajang lalangit Bulan (penutup bagian atas dari katil) atau sejenis atap yang dibentangkan dari kain panjang.

d. Lawang Timpung (suntai tali) yang digunakan untuk mengikat sanggar kambungan (jejahitan dari daun kelapa muda) yang disi dengan sipa rokok dan bungkusan beras yang ditempatkan diatas tempat duduk Basir.

e. Garantung (gong) 3 (tiga) Buah untuk tempat pijakan Basir pada saat pelaksanaan Balian.

f. Sangku yang berisikan beras. 
g. Tangkai beserta daun sirih, tandan pinang yang akan digantung di depan para Basir

h. Apar untuk tempat sesajen sangiang dan satu buah apar lagi tempat sesajen bagi ambun rutas matei

i. Tikar pasar yang dibentangkan didepan Katil (tempat duduk Basir) untuk menaruh peralatan upacara

j. Tambak Beras 3 (tiga) buah yang didalamnya berisi giling pinang , rokok, mata uang logam, bungkusan beras dari kain putih.

k. Gelas berisi air sebanyak 3 (tiga) buah dan juga disiapkan sirih pinang untuk sangiang.

1. Dawen Papas (Duan Papas), Salentup (bambu hijau) yang dipotong kira-kira nsatu buku sebanyak 7 (tujuh) buah, pisau tetesan ambun rutas matei (pisau), patung rotan, beras tatumbur, Gaharu manyan (kayu garu dan kemenyan), Parapen (Perapian),

m. Didepan pintu rumah dipasang bendera kuning sebagai petunjuk.

n. Tarinting Daun sawang (Daun Andong yang diikatkan dan diberikan tanda cacak burung atau tanda tambah) 
o. Amben (gendongan) dari rotan yang berisi batu asah serta sebuah botol yang berisi beras kuning, giling pinang dan rokok yang akan dipecahkan pada saat balian dimulai.

p. Pasuk kurung (bakul kecil dari anyaman) yang berisi patung dari kayu palawi (kayu ringan), bungkusan hambaruan, giling pinang, rokok.

q. Satu buang sangkut yag berisi kulit tambaran erang Tali Tengang (serat akar kayu tengang).

r. Pohon sawang (pohon Andong)

s. Ranying Pandereh Bunu (tumbak yang berbentuk tri sula)

t. Satu biji buah kelapa yang masih ada kulitnya

u. Satu buah gong berisi beberapa lembar pakaian, sisir, cermin dan minyak kelapa

v. 1 (satu) lembar Kain panjang untuk kampuh mihing, dan 1 (satu) lembar kain tantalai tawur.

w. 1 (satu) buah Mangkok panimba ambun rutas

x. Piring berisi beras yang beralaskan satu buah kain

y. 9 (sembilan) buah belahan bendang

z. 3 (tiga) ekor ayam dimasak, 2 (dua) ekor untuk untuk korban suci upacara tantulak Ambun Rutas Matei, 1 (satu) ekor lagi untuk 
sesajen ambun rutas matei dan Ketupat, kue-kue, telur ayam kampung secukupnya,

Keseluruhan perlengkapan upacara ini harus dipersiapkan sebelum pelaksanaan Tantulak Ambun Rutas Matei dilaksanakan dan sudah tersedia semuanya dirumah tempat berlangsung upacara tersebut, maka tepat pada hari ketiga setelah proses penguburan akan dimulai upacara Balian Tantulak Ambun Rutas Matei'

\section{Penyemputan Basir}

Dalam pelaksanaan penyemputan Basir menuju ke rumah tempat pelaksanaan upacara Tantulak Ambun Rutas matei haruslah berdasarkan aturan atau tata cara tertentu dimana Setelah tiga hari setelah proses upacara penguburan, maka keluarga yang ditinggalkan pergi menemui Basir Upu untuk memohon agar melaksanakan upacara Balian Tantulak Ambun Rutas Matei selanjutnya Basir Upu tersebut mencari 2 (dua) orang Basir Pengapit yang bertugas mendampinginya didalam pelaksanaan upacara Balian Tantulak Ambun Rutas Matei tersebut.

Tepat pada hari yang ditentukan atau tiga hari setelah proses penguburan Liau Haring Kaharingan, maka oleh keluarga yang berduka oleh Basir dari kediaman mereka masing-masing. Dan 
keberangkatan Basir dari rumahnya diatur Basir itu sendiri sesuai dengan petunjuk atau perasaan dari Basir tersebut. Apabila kata Basir berangkat, maka setelah keluar dari rumah Basir tersebut, keluarga yang menjemput itulah yang membawa (menjinjing) barang-barang yang dibawa oleh basir seperti Katambung dan tas barang dari Basir tersebut. Setelah Basir tiba di rumah tempat berlangsungnya upacara Tantulak Ambun Rutas Matei, sebelum masuk ke rumah, maka sebelumnya pihak keluarga pelaksana upacara mengadakan penyuncian para Basir dengan memakai daun sawang gagar (Daun Andong yang gugur) dan air cucian beras. Tujuan dari upacara pensucian ini adalah untuk melepaskan pengaruh-pengaruh buruk yang menganggu ditengah-tengah perjalanan para Basir, karena siapa yang tahu bahwa ada pertanda-pertanda buruk yang tidak dapat dilihat maupun yang tidak didengar ditengah perjalanan mereka menuju rumah tempat berlangsungnya upacara, sehingga pengaruh buruk tersebut terlepas sehingga para Basir yang melangsungkan upacara dapat berjalan dengan baik. Selesai upacara pensucian maka para Basir dapat dipersilahkan masuk.

\section{Pelaksanaan Upacara Tantulak Ambun Rutas Matei}


Pelaksanaan upacara Tantulak Ambun Rutas matei akan dilaksanakan selama satu hari penuh dan biasanya akan selesai pada keesokan harinya dimana prosesnya dimulai jika semua perlengkapan upacara telah diteliti oleh para Basir dan dinggap lengkap semuanya, dan para Basir sudah makan dan minum, maka sebelum basir memulai munduk Balian (duduk Balian) maka keluarga yang melaksanakan upacara melaksanakan upacara mamalas para Basir dengan memakai darah ayam sekaligus mengikat lilis lamiang pada setiap Basir satu persatu. Terkhusus kepada Basir Upu akan diikatkan emas seberat sajampal (Satu setengah gram), serta satu buah mata uang perak.

Basir memulai tugasnya, dimana Basir Upu melaksanakan manawur, dimana pada Beras Tawur yang dipakai dicampur dengan rincikan tampung papas, bambu salentup, curaian uang perak, curaian emas yang tujuannya adalah untuk memberitahukan terlebih dahulu kepada para sangiang bahwa mereka dipantai danum kalunen ada melaksanakan upacara Tantulak Ambun Rutas Matei, setelah upacara manawur selesai, maka para Basir melaksanakan Balian Nantilang Liau. 
Mengungkapkan bahwa kalimat iiiiiiii pada awal mulai Balian adalah mengandung pengertian bahwa IA Yang Maha Kuasa, awal dari segala-segalanya dan menjadi akhir segala-galanya, serta ucapan tersebut bertujuan untuk membuka pintu langit dan memuji namaNya.

Balian Nantilang Liau ini dilaksanakan setelah selesai Basir Upu manawur, dan kegiatan ini hanya dilakukan didalam kegiatan Tawur untuk mensucikan, membuang pengaruh-pengaruh buruk yang datang dari segala penjuru dari keluarga yang melaksanakan upacara, agar mereka selalu berada dalam keadaan suci bersih.

Setelah ayat Balian Nantilang Liau selesai dilanjutkan lagi dengan melantunkan mantram Balian Manjung Tawur sekaligus nyaluh tawur . Setelah melantunkan mantra-mantra Manjung Tawur dan Nyaluh Tawur selesai, selanjutnya para Basir mempersiapkan dirinya dengan beristirahat sejenak, setelah semuanya siap kemudian dilanjutkan lagi dengan Balian Mujan Balai, pengucapan Balian Mujan Balai adalah berisi pengucapan tentang proses pengenalan maksud dan tujuan kedatangan tawur yang datang ditengah-tengah mereka para Sangiang. mantra Mujan Balai seperti :

Mering merai tawur nanjung napus ruang balai Bahing jala Rambang nipas marung garing gantungae, Pusuk rawung baukei ninggang 
andau kasibahan, Bahing sahai mari masuh pasin bukit panjang, Bahing andau ujan rayu sarui ngandang silan langit, Petai ganggerang ngasuh nitih lambang bulan haragantung.....

\section{Artinya :}

Gemerincing suara tawur menghujani seluruh ruangan balai Bagaikan suara jala terlepas dari gantungannya, Gemuruh angin bertiup di pagi hari, Bagaikan suara arus air terjun di kaki bukit Gemuruh bunyi hujan di langit, Bagaikan gemuruh hujan dimalam hari.

Didalam pengucapan Balian Mujan Balai ini terdapat kalimat suci yang menyesuaikan dengan jenis upacara yang dilaksanakan. Setelah selesai Balian Mujan Balai selanjutnya diadakan Balian untuk menghadirkan Talawang jambu Bahandang menuju ke pantai danum kalunen, dan Sangiang Duhung Mama Tandang dihadirkan pula ke Pantai danum kalunen menuju ketempat upacara. Disinilah nantinya para sangiang akan tiba di pantai danum kalunen atau bumi ini menuju ke rumah pelaksanaan upacara Balian Tantulak Ambun Rutas Matei dan merasuk para Basir, setelah Sangiang yang turun tadi merasuk para Basir, maka para sangiang melakukan tugas pensucian atau melepaskan pengaruh buruk Ambun Rutas Matei dari keluarga yang terkena musibah meninggal dunia. Didalam pelaksanaan Balian ini dimana Sangiang telah merasuki para Basir yang melaksanakan upacara Tantulak Ambun Rutas Matei adalah berisi rangakaian perjalanan dari sangiang yang turun ke Pantai Danum kalunen untuk 
membersihkan keluarga yang mengalami musibah meninggal dunia dari segala sial dan pantangan-pantangan hidup, selanjutnya Sangiang Raja Duhung Mama Tandang yang telah merasuki para Basir melaksanakan Balian untuk Liau Haring Kaharingan (yang meninggal dunia).

Pelaksanaan Balian untuk Liau Haring Kaharingan ini yang mana dimulai ketika Sangiang Raja Duhung Mama Tandang berangkat menuju ke Bukit Pasahan Raung, tempat mengubur jenazah. Disini Sangiang Raja Duhung Mama Tandang bekerja dengan segala kesaktianya dan nantinya akan terjadi suatu dialog antara Sangiang Raja Duhung Mama Tandang dengan Liau Haring Kaharingan, dimana Liau Haring Kaharingan (orang yang meninggal dunia) pada awalnya tidak menyadari bahwa ia telah meninggal dunia, ia hanya merasa terbangun dari tidur panjangnya, disitu Sangiang Raja Duhung Mama Tandang menyadarkan Liau Haring Kaharingan dan menjelaskan kepadanya bahwa ia telah meninggalkan lewu injam tingang atau telah meninggal dunia. Setelah Liau Haring Kaharingan menyadari bahwa dirinya telah meninggal dunia maka ia menangis dan berkata-kata sampai hatinya Riwut Peres mengambil nyawaku, aku meninggal dunia bagaikan sebuah batu yang dilemparkan ke dasar sungai tidak 
mungkin akan kembali lagi, sedangkan aku masih ingin tinggal di Pantai Danum Kalunen. Setelah itu Raja Duhung Mama Tandang menesehati Liau Haring Kaharingan, jangan berbicara macam-macam cucuku, kamu memang sudah tiba waktunya sesuai janjimu dengan Ranying Hatalla Langit, dan sudah tiba saatnya kamu kembali ke Lewu Tatau (alam keabadian, kesempurnaan, dan kebebasan dari ikatan duniawi). Mendengar hal tersebut, barulah Liau Haring Kaharingan tersadar dan mengetahui bahwa dirinya benar-benar telah meninggalkan dunia ini, setelah itu Liau Haring Kaharingan menyucikan seluruh tubuhnya menghilangkan segala kesalahan dan kata-kata yang salah, menghilangkan segala sial selama ia hidup, sehingga setelah selesai Liau Haring Kaharingan di sucikan, ia terlihat bersih suci. Setelah itu Raja Duhung Mama Tandang berangkat bersama Liau Haring Kaharingan ke beberapa tempat untuk kembali membersihkan Liau Haring Kaharingan dan memohon agar Tarantang nule (orang yang ditinggalkan oleh Liau Haring Kaharingan) mendapatkan Penyang Karuhei Tatau (harta kekayaan). Setelah mendapatkan semuanya maka kembali mereka berdua berangkat lagi dan Raja Duhung Mama Tandang mengantar Liau Haring Kaharingan ke tempat-tempat yang pernah dialaminya dan didiaminya selama ia 
hidup, dan pada akhirnya Raja Duhung Mama Tandang dan Liau Haring Kaharingan tiba di rumah tempat berlangsungnya upacara Tantulak Ambun Rutas Matei. Liau Haring Kaharingan mengumpulkan seluruh keluarganya yang masih hidup dan menyampaikan pesan kepada mereka, menesehati mereka agar selalu hidup rukun, jangan sekali-kali membuat pertentangan. Selanjutnya Liau Haring Kaharingan meminta makanan, minuman serta giling pinang, rokok dan sebagainya sebagai akhir dari hidupnya kepada keluarganya yang telah ditinggalkan disini keluarganya memberikan segala yang diminta kepada Liau Haring Kaharingan yang telah merasuk ke Basir. Kemudian ini meminta kepada keluarganya untuk meneteskan minyak kelapa dirambutnya dan menyisir rambutnya supaya menjadi lurus, keluarganya lalu meneteskan minyak kelapa dan menyisir rambut Liau Haring Kaharingan tersebut. Bergantian seluruh anggota keluarga yang dekat meneteskan minytak kelapa dan menyisir rambut Liau Haring Kaharingan (dalam hal ini yang disisir adalah rambut basir yang telah dirasuki oleh Liau Haring Kaharingan). Setelah selesai semuanya maka Liau Haring Kaharingan meminta kepada seluruh keluarganya untuk berdiri dan memegang tangan Liau Haring Kaharingan karena Liau Haring Kaharingan ingin memberikan Kayun 
Penyang Karuhei Tatau (sumber dari harta kekayaan) supaya seluruh anggota keluarganya dapat hidup kaya raya, sehat dan sejahtera. Setelah selesai semuanya mennyalami Liau haring Kaharingan, maka Liau Haring Kaharingan mengeluarkan rasukannya dari Basir dan berjalan keluar rumah menuju ke Lasang Riwut (alat yang dipakai bersama Raja Duhung Mama Tandang tadi berangkat) dan terus terbang jauh, disini Raja Duhung Mama Tandang dan Liau Haring Kaharingan berangkat lagi ke beberapa tempat dan sampai di suatu tempat yaitu Lewu Bukit Nalian Lanting. Disinilah Raja Duhung Mama Tandang membangun rumah untuk tempat tinggal Liau Haring Kaharingan sementara menunggu pelaksanaan upacara Tiwah. Selesai semuanya maka Raja Duhung Mama Tandang kembali menuju Pantai Danum Kalunen ke rumah tempat pelaksanaan Upacara Tantulak Ambun Rutas Matei, dan memberitahukan kepada seluruh keluarga Liau Haring Kaharingan tentang Pantangan ambun Rutas dan pantangan Penyang karuhei Tatau. sebab jika mereka tidak dapat memelihara pantangan tersebut, apa yang sudah dipesankan kepada mereka, akan hilang begitu saja dan tidak ada artinya untuk kehidupan mereka. 
Balian Tantulak Ambun Rutas Matei dilanjutkan dengan Balian Pabuli Sangiang yang merasuk pada mereka, Basir serentak keluar dari rumah beserta sesajen sebagai imbalan jasa mereka. Dan ada dari pihak keluarga mengantar sesajen didalam ancak ke kuburan tempat liau Haring Kaharingan dikubur. Setelah itu Basir istirahat, biasanya upacara ini baru selesai pada subuh hari kira-kira pukul 2 atau 3 pagi.

\section{Pantangan pada Upacara Tantulak Ambun Rutas Matei}

Pada keesokan harinya lagi setelah para Basir sudah mandi serta makan, maka dilanjutkan lagi Balian Paturun Sangiang untuk merasuki para Basir dan pada Balian paturung Sangiang ini Sangiang Raja Duhung Mama Tandang menyampaikan besaran laluh lasan Sangiang yang bertugas serta menyampaikan pantangan Bulau Bambang Penyangnya. Adapun pantangan dan larangan-larangan yang tidak bisa dimakan oleh seluruh keluarga dari Liau Haring Kaharingan selama 7 (tujuh) hari setelah pelaksanaan Tantulak Ambun Rutas Matei yaitu :

a. Saluang Renteng Tantahan (ikan saluang merah)

b. Ucin Ngandang Batang (Jamur yang tumbuh dipohon kayu)

c. Ucin Ngandang Tana (jamur yang tumbuh ditanah)

d. Ujau, Bajei, Kalakai (rebung bambu, tumbuhan paku) 

e. Undang Salintip Kumpang (udang sungai yang kecil)
f. Tampala Leleng Hempeng (ikan tampala)
g. Janjulung Tusuk Samben (ikan janjulung)
h. Tatawun Ngarungkung Sahep ( ikan tatawun)
i. Buwui Himba (babi hutan)

Kemudian pantangan yang tidak boleh dimakan selama 3 (tiga) bulan yaitu :

a. Ranying Manjuhan (ikan manjuhan)

b. Tungkul Pisang Munus (jantung pisang)

c. Singkah Uhut (pucuk rotan)

d. Bua Botong (buah botong)

e. Palanduk Sumping Taliwu (Kancil)

f. Karahau Batunjang Bintang (Menjangan)

g. Bajang kalingkai lawung (Rusa)

Setelah semuanya telah disampaikan, Basir mengadakan Balian Pabuli sangiang dimana Sangiang kembali ketempatnya yaitu ke Batang Danum Jalayan, maka selesailah seluruh upacara Tantulak Ambun Rutas Matei. Basir yang melaksanakan upacara Tantulak Ambun Rutas Matei dapat diantar kembali kerumahnya masing-masing oleh anggota Keluarga. 


\section{B. Perspektif Hukum Hindu}

Menurut Daryanto (2008:49) dalam Kamus Besar Bahasa Indonesia perspektif adalah sudut pandang atau pandangan berarti pendapat atau interprestasi terhadap sesuatu yang dilihat dari salah satu wujud yang dianggap relevan terhadap substansi atau topik masalah yang diangkat. Dalam penulisan ini perspektif merupakan pendapat atau pandangan yang berfungsi untuk mengkaji tentang upacara Tantulak Ambun Rutas Matei dari kitab suci Panaturan sebagai sumber Hukum Hindu Kaharingan yang tertulis pada pasal 56 tentang Bawi Ayah Nantu Ajar Auh Talatah Tantulak Ambun Rutas Matei. Sedangkan konsep Hukum Hindu yang tersurat dalam beberapa susastra Hindu merupakan upaya penting dalam dunia pendidikan dan juga untuk memenuhi harapan umat Hindu untuk memenuhi konsep Hukum Hindu dalam kehidupan sehari-hari pada masyarakat, hal ini sebagaimana tertulis dalam Kitab Manawa Dharmasastra II.6. yang berbunyi :

Vedokilo dharmamulan, smrti sile ca tad vidam, acara Saiwa sadhunan atmanastuti rewasca.

Artinya : 
Weda Sruti adalah sumber pertama dari pada dharma, kemudian baru smerti, disamping sila, acara dan atmanastuti." (Gde Pudja, Sidharta, Tjokorda Rai 2002:7).

Bunyi sloka tersebut diatas telah memberikan pengayoman bahwa semua aktivitas ritual yang dilakukan oleh umat yHindu dimanapun berada adalah merupakan ajaran yang benar sesuai acara dan atmanastuti misalnya masyakarat Hindu Kaharingan di Kalimantan Tengah melakukan upacara Ritual Tantulak Ambun Rutas Matei berupakan bagian dari pitra yadnya yang wajib dilaksanakan oleh umat Hindu Kaharingan.

Hukum Hindu telah banyak ditulis dalam beberapa tulisan oleh pakarnya, seperti menurut (Surpha, 2005:2) dinyatakan bahwa "bentuk Hukum Tuhan yang murni dalam ajaran agama Hindu disebut $r t a$ atau rita, yaitu Hukum murni yang bersifat absolute transcendental. Rita ini kemudian dijabarkan kedalam tingkah laku manusia dan disebut dharma. Adapun Hukum agama yang disebut dharma itu sifatnya relative, karena ia selalu dikaitkan dengan pengalaman manusia dalam mengatur tingkah manusia untuk mencapai kebahagiaan didalam kehidupannya". Istilah lain mengenai Hukum Hindu selain yang disebut diatas adalah Vidhi. Kata $r t a$ berarti Hukum yang abadi atau Hukum yang alami. Sedangkan 
dharma berarti mengatur, menuntun, menjunjung, kebenaran dan agama. Kata dharma lebih banyak menekankan pada makna Hukum agama Hindu. Ada juga istilah yang disebutkan dengan susila yakni tata aturan yang mengatur tentang perilaku yang baik bagi manusia. Bila tata aturan agama Hindu yang dilanggar oleh umatnya, maka hal itu tegolong asusila atau perilaku yang menyimpang dengan tata aturan Hukum Hindu atau ajaran-ajaran agama Hindu. Kata Vidhi sesungguhnya adalah Hukum yang bersifat niskala dari kebesaran dan kemahakuasaan yang tertinggi dari tuhan Yang Maha Esa, yang sering disebut Ida Sang Hyang Widhi Wasa, yang dalam bahasa lokal juga dinamakan Ranying Hatalla Langit. Jadi Perspektif Hukum Hindu adalah merupakan sudut pandang dari susastra Hindu baik dari Kitab Suci Weda maupun Kitab Suci Panaturan sebagai sumber hukum Hindu yang mengatur, menuntun, menjunjung, kebenaran dan agama.

\section{PENUTUP}

Latar belakang pelaksanaan upacara Tantulak Ambun Rutas Matei adalah merupakan suatu kewajiban yang harus dilaksanakan oleh seluruh umat Hindu Kaharingan jika ada anggota keluarga yang mengalami kematian. Dasar pelaksanaannya adalah bersumber kepada Kitab Suci 
Panaturan yang dulunya pernah diadakan di Lewu Bukit Batu Nintan Tarung pada pelaksanaan upacara Tiwah Suntu Raja Pampulau Hawun. Selanjutnya diajarkan kembali oleh Bawi Ayah kepada anak keturunan Raja Bunu di pantai Danum kalunen (bumi) sebagai contoh yang harus dilaksanakan. Mengapa upacara Tantulak Ambun Rutas Matei ini dilaksanakan oleh Umat Hindu Kaharingan, hal ini dikarenakan bahwa kepercayaan bagi umat Hindu Kaharingan jika ada keluarganya yang meninggal dunia akan terjadi sial pali akibat dari kematian tersebut. Terjadinya sial pali belum (sial didalam kehidupan) akibat dari kematian tersebut, dimana seluruh anggota keluarga berduka cita, muncul perasaan sedih yang mendalam, pikiran yang kacau balau sehingga tidak sanggup lagi untuk memikirkan apapun, untuk menghilangkan sial pali belum tersebut, maka diadakanlah upacara Balian Tantulak Ambun Rutas Matei tersebut. Melalui upacara Tantulak Ambun Rutas Matei ini juga merupakan suatu proses pengantar arwah Liau Haring Kaharingan naik menuju ke Lewu Bukit Nalian Lanting, Rundung Kereng Naliwu Rahan dimana arwah Liau Haring Kaharingan tersebut ikut bersama Balu Indu Rangkang Penyang di batang danum Baras Bulau, Guhung Sating Malelak Hintan, disanalah Liau Haring Kaharingan menunggu sampai waktunya pihak keluarganya yang masih hidup melaksanakan upacara Tiwah yaitu mengantar Liau 
Haring Kaharingan ke Lewu Tatau Habaras Bulau Habusung Hintan Karangan Lamiang Lewu Dia umpang Tulang Rundung Raja Isen Kamalesu Uhat (Alam keabadian, kesempurnaan dan kelepasan). 


\section{DAFTAR PUSTAKA}

Daryanto. 2008. Kamus Bahasa Indonesia, Surabaya; APOLLO.

Koentjaraningrat, 1987, Sejarah Teori antropologi, Jakarta, Universitas Indonesia

Kabinet Indonesia Bersatu Periode 2004-2009, Undang-Undang Dasar Negara Republik Indonesia 1945 dan Amandemennya, Jakarta : Penerbit Team Media.

Koentjaraningrat. 1985. Beberapa Pokok Antropologi Sosial. Jakarta: Dian Rakyat.

Pendit, Nyoman S, 1993. Aspek-aspek Agama Hindu. Surabaya : Paramita.

Pudja, Gde dan Sidharta, Tjokorda Rai, 2002. Manawa Dharmasastra, Jakarta : Pelita Nursatama Lestari.

Tim Penyusun, 2005. Kamus Besar Bahasa Indonesia, Balai Pustaka, Jakarta

Tim Penyusun. 2013. Panaturan. Denpasar: Widya Dharma

Surpha, I Wayan. 2005. Pengantar Hukum Hindu. Surabaya. Paramita 